\title{
Volume 2 Issue 5
}

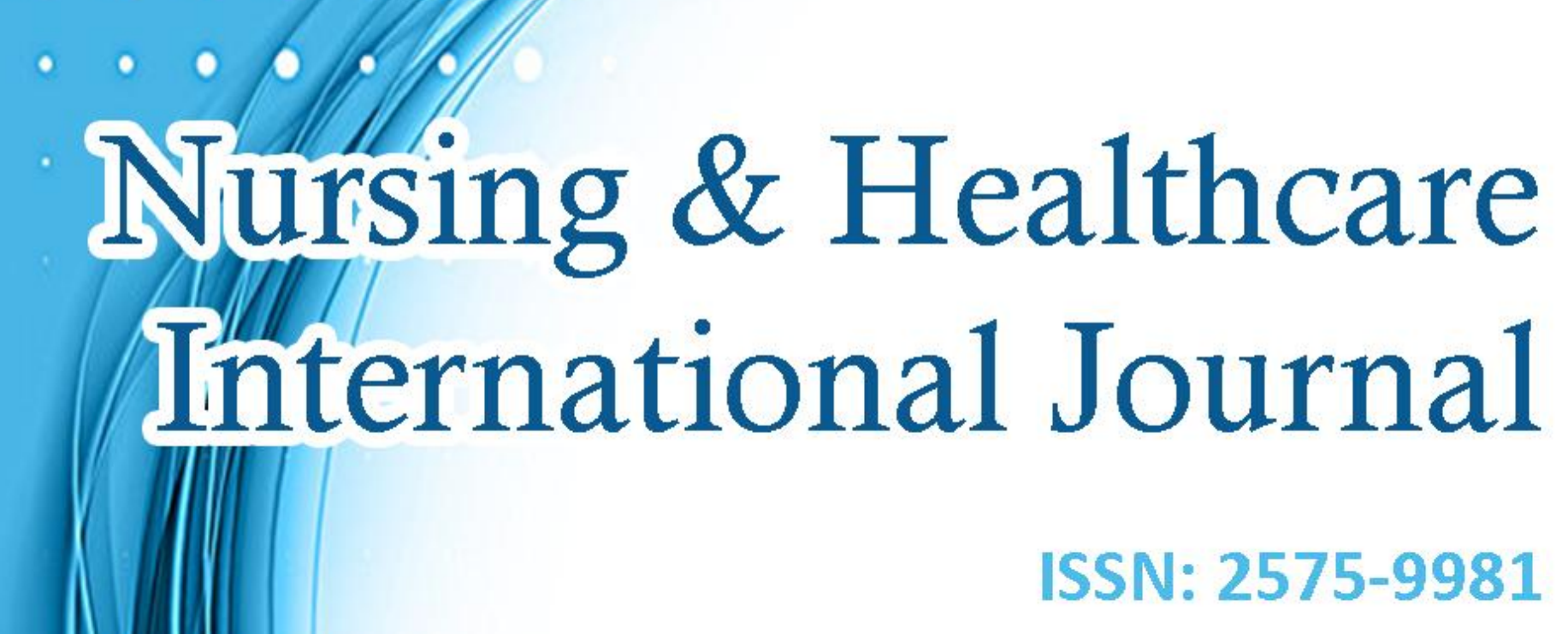

0

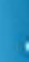




\title{
Health Professionals' perceptions and Experiences of Family \\ Caregivers: A Pilot Qualitative Study Carried Out at the Diabetes Centre of the National Public Health Institute of Cote d'Ivoire
}

\author{
Kourouma $\mathrm{KR}^{1 *}$, Agbre Yace $\mathrm{ML}^{1}$, Doukoure $\mathrm{D}^{1}$, Tano Kamelan $\mathrm{Y}^{1}$, \\ N’Dia Anon F ${ }^{2}$, Acka KF1, Aka J1, Aké 0 ${ }^{1}$, Aké M11 and Kouassi D ${ }^{1}$ \\ ${ }^{1}$ Institut National de Santé Publique, Côte d'Ivoire \\ 2Université Félix Houphouet Boigny d' Abidjan, Côte d'Ivoire
}

Research Article

Volume 2 Issue 5

Received Date: July 07, 2018

Published Date: July 31, 2018

*Corresponding author: Kourouma Kadidiatou Raissa, Institut National de Santé Publique, BPV 47 Côte d'Ivoire, Tel: +22540766850; Email: kkouroum@gmail.com

\section{Abstract}

Introduction: Despite a growing interest in proximology about the relationship between family caregivers of people with non communicable disease such as diabetes and health professionals, little is known about this issue in Côte d'Ivoire. While researchers are focused on diabetic patient, they frequently omit health professionals' experiences with family caregivers. This paper aims to report a study on the perception of health professionals of family caregivers of diabetic patient and identify the facilitating factors to improve their implication in the care process.

Material and Method: This qualitative research using semi structured interviews was conducted between February and April 2018, among the health workers $(n=17)$ of the Diabetes Centre of the Public Health Institute of Côte d'Ivoire. Data were analyzed using a content and thematic analysis of the transcripts.

Results: The health professional expressed in general a good perception of caregivers despite conflicts. According to them, information and education on diabetes, improvement of the organizational practices, recruitment of a social worker, recognition of the caregivers' expertise and work, organization of discussion group and creation of an association of family caregivers of people with diabetes are facilitating factors to improve caregivers' implication.

Conclusion: This study revealed that there is a need for greater awareness among health professionals concerning the expectations and needs of caregivers. Health professionals also need to be trained in family caregivers/patient/ health professional relationship in order to understand this relational issue and set up essential partnership that conditions the quality, continuity and effectiveness of home care.

Keywords: Family caregivers; Healthcare services; Diabetes; Côte d'Ivoire 


\section{Nursing \& Healthcare International Journal}

\section{Introduction}

Worldwide, the prevalence of non communicable, chronic diseases such as diabetes is increasing at an alarming rate. Indeed, according to the World Health Organization (WHO), in 2015, an estimated 1.6 million of death were directly attributable to diabetes [1].

Diabetes is a growing public health concern, notably because of its impact on the society, the health system and the individual affected by the disease. To manage the disease, people with diabetes need the support of their family. Much of a patient's diabetes management takes place within their family and social environment. Addressing the family environment for adults with diabetes is important since this is the context in which the majority of disease management occurs [2].

In recognition of the fact that family can serve as a cotherapist, recent treatments and changes in health policy have led to a shift in care from hospital to home care; with a part of the responsibility for care then resting with the patient's family [3].

At home, a large part of help for patients is provided by relatives and not by professional caregivers [4]. The treatment is therefore part of a triangular relationship between family/Patient/healthcare professional (HP); so that the healthcare professionals are led to understand the relationship issues of communication.

Indeed, poor relationship between HP and family caregivers may have repercussions on adherence to treatment and the continuity or the quality of care at home. In addition, HPs' lack of explicit attention to family caregivers is a serious gap in health care in light of the more than two decades of research that documents the potential hazards of family care giving. Family caregivers are hidden patients themselves, with serious adverse physical and mental health consequences from their physically and emotionally demanding work as caregivers and reduced attention to their own health and health care [5].

A few researchers have collected data from both family caregivers and HPs about how they work together in providing care $[6,7]$ or how that relationship changes over time [8]. Others researchers have concluded that negotiation of partnership between healthcare professionals and family caregivers is a dynamic process that involves considerable conflict [9-11].
In Côte d'Ivoire, where the prevalence of diabetes is around $4.94 \%$ according to the International Diabetes Federation, very little is known about relationships between HPs and family caregivers when people with diabetes ongoing needs are cared for at home by family caregivers.

Thus, as part of the National Public Health Institute of Côte d'Ivoire (INSP) policy of continuous improvement in the quality of care and continuity of home care for diabetic patients followed up at the Diabetes Center (CADA), we performed this study with the objectives to understand the health professional perception of the family caregivers and to identify facilitating factors that can strengthen the caregivers' implication in the care process.

\section{Materials and Methods}

\section{Study Design and Procedure}

This qualitative research is part of a larger study on the relationship between family caregivers, diabetic patient and HPs, performed in CADA. CADA, whose mission is the outpatient management of diabetic patient with an active line of more than 57,000 patients up to date, receives in average 50 patients per day. The nursing team includes twelve doctors, four nurses and one nurse aid. The data reported in this paper come from semistructured interviews with HPs.

The study was conducted between February and April 2018 on all the HPs working at CADA $(n=17)$. The questions of the interview guide asked during the interviews were based on a review of the literature [12] and objectives were focused on the HPs' views and experiences with family caregivers, and the facilitating factors that can reinforce the involvement of the family caregivers $\mathrm{a}$ in the care process. The themes were explored using open-ended questions.

The interview guide was pre-tested on the sample of 8 health professionals on February 2, 2018. This pre-test helped us to improve the content of the interview guide. The semi-structured interviews were conducted face to face in the HP office by one investigator. Appointments were preferably made outside working hours and took place in a room where doctors felt comfortable. Informed consent was sought before each interview began. The interviews were tape-recorded. 


\section{Statistical Analysis}

The semi-structured interviews data were analyzed following recommended guidelines for qualitative research. The data collected from interviews were transcribed in their entirety, coded and analyzed using a content and thematic analysis of the transcripts [13]. Concerning the theme identified, as each HP gave many responses; we organized the responses into item. For each item we calculated the percentage of responses related to the item by divided the number of responses given related to this item out of the total of responses given for all the items using Excel.

\section{Ethical Issues}

The participants were informed in a letter about the aim of the research project and what participation in semi-structured interviews meant. They were all informed that the participation was voluntary and that confidentiality would be secured throughout the research process. Informed consent was sought before each interview.

\section{Results}

The main identified themes were: HPs view of family caregivers' role; consequences of conflict or poor relationship between HPs and family caregivers and facilitating factors for a better implication of family caregivers.

\section{Health Professionals View of Family Caregivers' Role}

As displayed in Table 1, the data of the interviews showed that for HPs working in CADA, the family caregivers play an important role. Indeed $21 \%$ of the total answers were related to their role as a second health worker, $19.8 \%$ to their role as a relay between the patient and HPs and $18.5 \%$ to their help in reformulating and translating instruction for illiterate patient who do not speak french. Moreover, they represent an important source of information on the patient. HPs interviewed, also recognized the work load and the quality of work done by the family caregivers. However some family caregivers can be stressful for the patient as explained by two HPs:

"A woman came here with her hemiplegic mother, after having waited for long; she started to get angry at her mother. Then she asked us at what time her mother will be checked by the doctor because her husband's mother was alone at home and she had no time to wait, she had to go to take care to her mother-in-law. I told her that diabetes is hereditary, and that one day she may find herself in her mother's situation and her child will refuse to take care of her." HP9

"Often the accompanying person stresses the patient. During consultations they press the patient because they themselves are in a hurry to leave. HP3

\begin{tabular}{|c|c|c|}
\hline Items & Frequencies & $\mathbf{\%}$ \\
\hline $\begin{array}{c}\text { Family caregiver help in } \\
\text { reformulating and translating the } \\
\text { instruction for illiterate patient }\end{array}$ & 15 & 18.5 \\
\hline $\begin{array}{c}\text { Family caregiver an important } \\
\text { source of information concerning } \\
\text { the patient }\end{array}$ & 10 & 12.3 \\
\hline $\begin{array}{c}\text { Family caregiver as a relay } \\
\text { between patient and HPs }\end{array}$ & 16 & 19.8 \\
\hline $\begin{array}{c}\text { Family caregiver as a second } \\
\text { health worker }\end{array}$ & 17 & 21 \\
\hline $\begin{array}{c}\text { Family caregivers as a financial } \\
\text { and physical support }\end{array}$ & 16 & 19.8 \\
\hline $\begin{array}{c}\text { Family caregivers can be stressful } \\
\text { for the patient }\end{array}$ & 7 & 8.6 \\
\hline Total responses & 81 & 100 \\
\hline
\end{tabular}

Table 1: Percentage of responses related to health professionals view of family caregivers' role.

\section{Consequences of conflict or Poor Relationship between Hps and Family Caregivers}

Out of the HPs interviewed; only three of them declared never having experienced a situation where caregivers had a hostile attitude towards them. Those who experienced such a situation, the mains reasons of conflict are the behavior of family caregivers and organizational issue as explained below:

"We meet many caregivers who have a hostile behavior towards us; they already form a wrong idea of health workers. One day we experienced a scene here, a man who accompanied his sick mother, but the doctor came late and in addition the nurse had filed the file in the office of the doctor without taking the constant. That's when the patient's son became angry and started to insult everyone." HP15

Concerning the consequences of poor relationship or conflict with family caregivers, as displayed on Figure1: $20 \%$ of the responses were related to the lack of compliance, $18.8 \%$ to the rapid occurrence of 
complications, and $17.6 \%$ to the abandonment of the health structure for another.

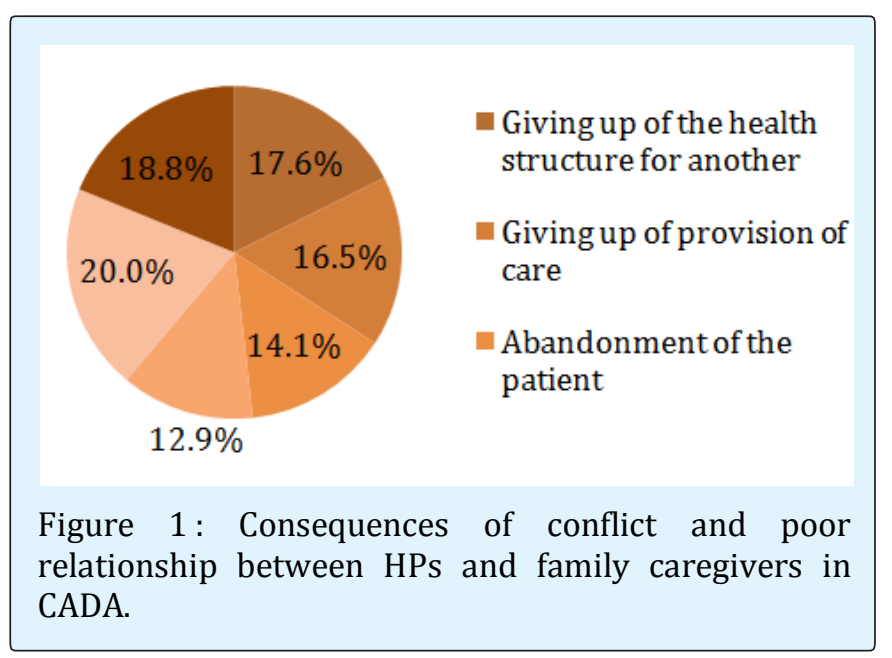

\section{Facilitating Factors for a Better Implication of Family Caregivers}

As illustrated in Table 2, the main facilitating factors reported by HPs were in terms of percentage of given responses: more information and education of caregivers on diabetes $(22.7 \%)$, good waiting time conditions (22.7\%), and the organization of discussion group (20\%), good management of appointment and the recognition of the work done by the family caregivers $12 \%$ respectively, the creation of an association of family caregivers (9.3\%) and the recruitment of a social worker (1.3\%).

\begin{tabular}{|c|c|c|}
\hline Items & Frequencies & $\mathbf{\%}$ \\
\hline Good waiting time conditions & 17 & 22.7 \\
\hline Good management of appointment & 9 & 12 \\
\hline $\begin{array}{c}\text { More information and education of } \\
\text { family caregivers }\end{array}$ & 17 & 22.7 \\
\hline $\begin{array}{c}\text { Organization of discussion group for } \\
\text { experience sharing }\end{array}$ & 15 & 20 \\
\hline $\begin{array}{c}\text { Creation of an association of family } \\
\text { caregivers }\end{array}$ & 7 & 9.3 \\
\hline $\begin{array}{c}\text { The recognition of the work done by } \\
\text { the family caregivers }\end{array}$ & 9 & 12 \\
\hline Recruitment of a social worker & 1 & 1.3 \\
\hline Total responses & 75 & 100 \\
\hline
\end{tabular}

Table 2: Percentage of responses related to facilitating factors for caregivers' involvement.

\section{Discussion}

The aim of this study is to contribute to improving the family caregiver/health professional relationship at the Diabetes Centre of the National Public Health Institute of Côte d'Ivoire, through the establishment of a true partnership. To this end, we carried out this qualitative study to evaluate this relationship in practice and identify the elements that could strengthen the implication of the family caregivers in the care process.

\section{Study Limitation and Strength}

The limitation of our study is linked to the chosen method: the qualitative approach using semi-structured interviews. This study dealing with a sensitive subject related to quality of care, may induce a refusal to answer that is difficult to interpret.

The strength of our study consists in its originality because it is the first proximology study performed at CADA Moreover, this study is part of a context where HPs working at CADA, are desirous to establish a family caregiver/patient/ health worker partnership. To succeed in this partnership, the HPs should evolve towards patients and caregivers. To this end, it is essential to know these two actors through the development of proximology within CADA. The originality of this new area of research is to consider the role of family caregivers as determining factors in the patient's environment, and therefore the effectiveness of the disease management and care. [14].

This study will be extended at national scale, to other health facilities, in order to gather the maximum of information concerning this issue.

\section{Health Professionals View of Family Caregivers' Role}

In our study, according to HPs, family caregivers are between usefulness and stressfulness. Indeed HPs recognized the essential role that family caregivers play in home care such as translating the medical instructions and followed their application at home, helping in taking the treatment, monitoring the diet and can also playing an important role in preventing relapses or crises; in a context where $30 \%$ of the diabetic patients are illiterate [15]. However they also highlighted the fact that can also be stressful for the patient, because they have their own activities and they have to take in their time to help their diabetic relative.

In a study performed by IPSOS Santé in 2008, in France, $90 \%$ of the HPs surveyed believe that the role of family and friends in the care of sick people is likely to 
develop in the coming years and $76 \%$ consider that family and friends are more visible and interactive with them than they were ten years ago [16]. The same study revealed that $96 \%$ of the HPs interviewed believe that family caregivers could be a true partner in care. As such, they recognized their beneficial role in terms of health economics, since $81 \%$ of them believe that the contribution of family and friends could help to reduce health expenditures [16].

\section{Consequences of Conflict or Poor Relationship between Hps and Family Caregivers}

HPs interviewed in our study have in general a good relationship with family caregivers and they are also aware that a poor relationship with caregivers can have an impact on the quality and continuity of home care. Most of time, conflicts between HPs and caregivers are also due to organizational issues. In spite of conflicts, of bad behavior of certain family caregivers, HPs struggle to maintain a good relationship with caregivers. All the HPs interviewed related that a poor HPs/family caregivers could lead to the following problems: giving up of the health structure for others, refusal to translate the HPs' instructions to the diabetic patient, change in health structure, abandonment of the patient, lack of compliance with treatment, rapid occurrence of complications.

Therefore, more attention should be given to family caregivers because they are often, exhausted, stressed and get sick [17]. The IPSOS study showed that $78 \%$ of the doctors say that they pay attention to caregivers' health, $90 \%$ give them advice on how to protect themselves and $85 \%$ make sure they can contact them easily. However, one half of HPs say they "always" adopt its behavior, the other half "sometimes"[16].

Even if the presence of family caregivers is generally considered beneficial for the patient, it is far from without difficulties. Health professionals find themselves dealing with conflicts between but also come into conflict with the latter as our study showed. Indeed in our study, most of time, conflicts were related to organizational issues in the management of appointment and the waiting time. Coherent organization of care, quality of care, organization of dialogue between HPs and caregivers, the fact of better understanding families and avoiding creating the conditions for conflict are important to appease strains with the patients' caregivers [18].

\section{Facilitating Factors a Better Implication of Family Caregivers}

As for involving more caregivers in the care process, the HPs interviewed in our study consider that information and education on diabetes, improvement of the organizational practices, recruitment of a social worker, recognition of the caregivers' expertise and work, organization of discussion group and creation of an association of family caregivers of people with diabetes are facilitating factors to improve caregivers' involvement.

The establishment of an association of family caregivers of people suffering from diabetes, the organization of discussion group could enable CADA's health workers to be attentive to the needs and expectations of caregivers and also pay attention to their health which can have an influence on the quality and continuity of home care.

Concerning the recognition of their expertise and work done, these results are similar to those obtain by Ong [19] who found that family caregivers valued being treated as equals and with respect by community nurses. When asked about their caring work in relationship to that of the nurse, family caregivers claimed to have unique knowledge about the care recipient and specific expertise needed to personalize care. They expected these to be acknowledged as an indication of preferred role as full partner in care $[19,20]$.

In the IPSOS study, the HPs to involve caregivers take into account: their motivation, their availability and finally their abilities or skills. The will expressed by the patient appears only last [16].

These results obtained in France, compared to those of our study show the importance of knowing the caregivers. Indeed, training and sensitization certainly have their importance, but it is fundamental to know the caregivers in all their dimensions such as expectations and needs. It is also important to exchange with them on what could really get them to become more involve in care. Besides, the establishment of a partnership family caregivers/ health professionals necessarily requires a training of health workers in this domain but also the implementation of policies to support this partnership in the Ivorian healthcare system.

This study is part of a context where HPs working at CADA, are desirous to establish a family caregiver/patient/ health worker partnership. To succeed in this partnership, the HPs should evolve towards patients and caregivers. To this end, it is essential to know 


\section{Nursing \& Healthcare International Journal}

these two actors through the development of proximology within CADA. The originality of this new area of research is to consider the role of family caregivers as determining factors in the patient's environment, and therefore the effectiveness of the disease management and care [14].

\section{Conclusion}

The development of aid relationship within professional practices is an important progress in the quality and efficiency of care. Diabetes as many non communicable diseases, is part of a relationship family caregiver/patient/health professional. Health professionals are therefore led to understand this relational issue to set up essential partnership that conditions the quality, continuity and effectiveness of home care. They are also led to develop a quality of behavior that aims, beyond providing care, to accompany the diabetic patient and his family caregivers in listening and respecting all singularities.

\section{Acknowledgments}

We would like to thank all the health workers of CADA for having accepted to participate in the study and for their availability.

\section{Conflict of Interest}

Authors declare no conflict of interest.

\section{References}

1. WHO (2018) consulté le 23 mars World Health Organization.

2. WHO (2002) Innovative care for chronic conditions: building blocks for action: global report. Geneva: Noncommunicable Disease and Mental Health Cluster World Health Organization.

3. Van den Bos GAM (1995) The burden of chronic diseases in terms of disability, use of health care and healthy life expectancies. Eur J Public Health 5(1): 2934.

4. Emanuel EJ, Fairclough DL, Slutsman J, Alpert H, Baldwin D, et al. (1999) Assistance from family members, friends, paid care givers, and volunteers in the care of terminally ill patients. $\mathrm{N}$ Eng J Med 341(13): 956-963.
5. Reinhard SC, Given B, Petlick NH, Bemis A (2008) Supporting family caregivers in providing care. In: Hughes RG (eds), Source Patient Safety and Quality: An Evidence-Based Handbook for Nurses. Rockville (MD): Agency for Healthcare Research and Quality (US); Chapter 14. Advances in Patient Safety.

6. Fischer LR, Eustis NN (1994) Care at home: family caregivers and home care workers. In: Kahana, et al. (eds), Family Caregiving across the Lifespan. Thousand Oaks, CA: Sage.

7. Twigg J, Atkin K (1994) Carers Perceived: Policy and Practice in Informal Care. Philadelphia: Open University Press.

8. Clark CA, Corcoran M, Gitlin LN (1994) An exploratory study of how occupational therapists develop therapeutic relationships with family caregivers. Am J Occup Ther 49(7): 587-594.

9. Frank father DL (1981) Provider discretion and consumer preference in long-term care of seriously disabled elderly. Gerontologist 21(4): 366-373.

10. McKeever P (1992) Mothering Chronically-Ill, Technology Dependent Children: An Analysis Using Critical Theory, Ontario: York University, Dissertation, Toronto.

11. Thorne S, Robinson C (1989) Guarded alliance: health care relationships in chronic illness. Image J Nurs Schol 21(3): 153-157.

12. Bauer M, Nay R (2003) Family and staff partnerships in long-term care: A review of the literature. Journal of gerontological nursing 29(10): 46-53.

13. Guest GS, MacQueen KM, Namey EE (2012) Applied thematic analysis. Thousand Oaks: Sage.

14. Proximology, Perspectives on the entourage of sick, dependent or disabled people, coord. and preface by Hugues Joublin, p. XI.

15. Kourouma KR, Yapi A, Acka KF (2016) Health insurance coverage: a cross-sectional study among patients followed at the diabetes centre of Abidjan Cote d'Ivoire (CADA). Int J Cur Res Rev 8(6): 35-39.

16. (2008) Ipsos Health for Novartis - Healthcare Professionals and Patient Care. 


\section{Nursing \& Healthcare International Journal}

17. Turcotte, Martin (2013) Being a family caregiver: what are the consequences? Ottawa: Statistics Canada.

18. Moriceau, Michel, Philippe Colombat (2001) Conflict Management with Families, InfoKara 16(4).
19. Ong BN (1990) Researching needs in district nursing. J Adv Nurs 16(6): 638-647.

20. Hasselkus B (1992) Physician and family caregiver in the medical setting: negotiation of care. J Aging Stud 6(1): 67-80.

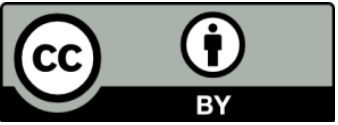

